\title{
Correction to "Synergistic Effects of Acetyl-L-Carnitine and Adipose-Derived Stromal Cells on Improving Regenerative Capacity of Acellular Nerve Allograft in Sciatic Nerve Defect"
}

In Figure 2B of the above article [Mohammad-Bagher G, Arash A, Morteza B-R, Naser M-S, and Ali M (2019) J Pharmacol Exp Ther 368(3): 490-502; DOI: https://doi.org/10.1124/ jpet.118.254540], the authors discovered the arrows pointing to the nerve fibers (axons and myelin sheathes) are missing. The correct version of Figure 2 is provided below. Also note, the email address for the Corresponding Author email has been updated: behnam@um.ac.ir.

The authors apologize for any inconvenience this may have caused.
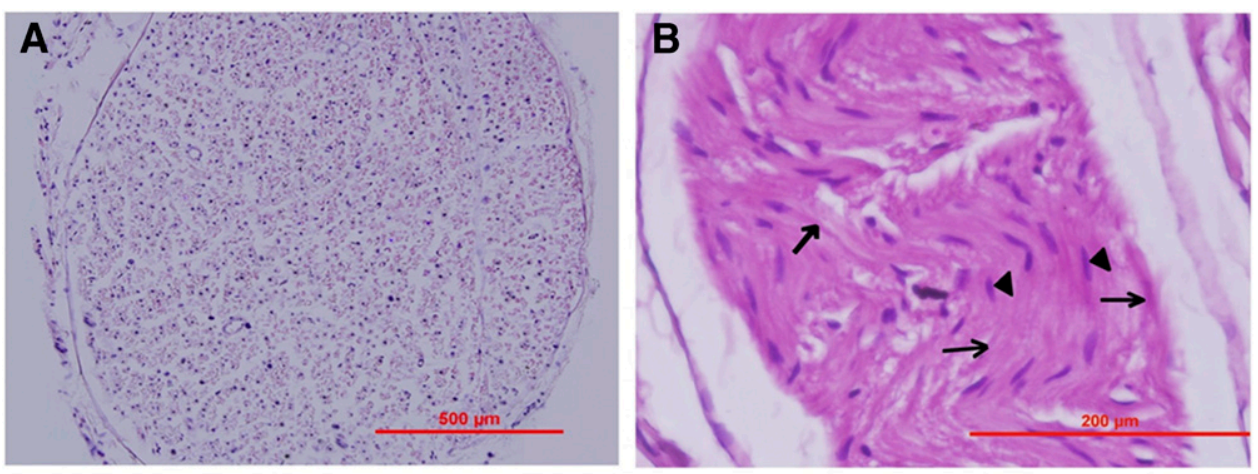

C

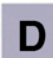

